\title{
Microcontroller-Based Improved Predictive Current Controlled VSI for Single-Phase Grid-Connected Systems
}

\author{
Yousry Atia $^{\dagger}$ and Mahmoud Salem* \\ $\dagger^{*}$ Electronics Research Institute, Giza, Egypt
}

\begin{abstract}
Predictive current control offers the potential for achieving more precise current control with a minimum of distortion and harmonic noise. However, the predictive method is difficult to implement and has a greater computational burden. This paper introduces a theoretical analysis and experimental verification for an improved predictive current control technique applied to single phase grid connected voltage source inverters (VSI). The proposed technique has simple calculations. An ATmega1280 microcontroller board is used to implement the proposed technique for a simpler and cheaper control system. To enhance the current performance and to obtain a minimum of current THD, an improved tri-level PWM switching strategy is proposed. The proposed switching strategy uses six operation modes instead of four as in the traditional strategy. Simulation results are presented to demonstrate the system performance with the improved switching strategy and its effect on current performance. The presented experimental results verify that the proposed technique can be implemented using fixed point 8-bit microcontroller to obtain excellent results.
\end{abstract}

Key words: Grid connected system, Microcontroller, Predictive current controller, Single phase VSI

\section{INTRODUCTION}

In recent years, due to growing concerns over energy shortages and network stability, the concepts of distributed generation (DG), and hybrid power systems have become progressively more popular [1]. With the decreasing costs of various clean renewable energy sources, such as wind, solar, and fuel-cells, they are becoming more attractive for feeding the utility grid from renewable sources. For an inverter-based distributed generator, the power quality largely depends on performance of the inverter controller [2], [3]. Pulse width modulation (PWM) is the most popular control technique for grid-connected inverters. When compared with open loop voltage PWM converters, current-controlled PWM has several advantages such as fast dynamic response, inherent over-current protection, good dc link utilization, peak current

Manuscript received Mar. 9, 2013; revised Sep. 10, 2013

Recommended for publication by Associate Editor Se-Kyo Chung.

†Corresponding Author: yousry_atia@yahoo.com

Tel: +20-2-33310512, Fax: +20-2-33351631, Electronics Research Institute

*Electronics Research Institute, Giza, Egypt protection, ...etc. [4].

In the case of single-phase full-bridge voltage-source inverters, two PWM switching strategies for voltage control can be employed [5]-[7]. The first strategy is the bi-level switching strategy, where the inverter output voltage switches between the positive and negative inverter input dc source. The second strategy is the tri-level switching strategy, where the inverter output voltage switches between the positive (or negative) inverter input dc source and zero.

Simulation of bi-level and tri-level current controlled systems indicates that many advantages can be gained by using tri-level switching such as a reduced current ripple and a halved switching frequency. The main disadvantage of the tri-level switching strategy is controlling the power switches at the voltage crossover. Care must be taken to ensure that adequate control over the current is maintained. This tends to make the controllers more complicated than the bi-level equivalent [5]. This problem is clearly found in the theoretical and experimental results of [8]-[13]. This paper introduces a solution for this problem which is one of its contributions, where six modes of operations (instead of four) are used to develop the proposed tri-level switching strategy. 


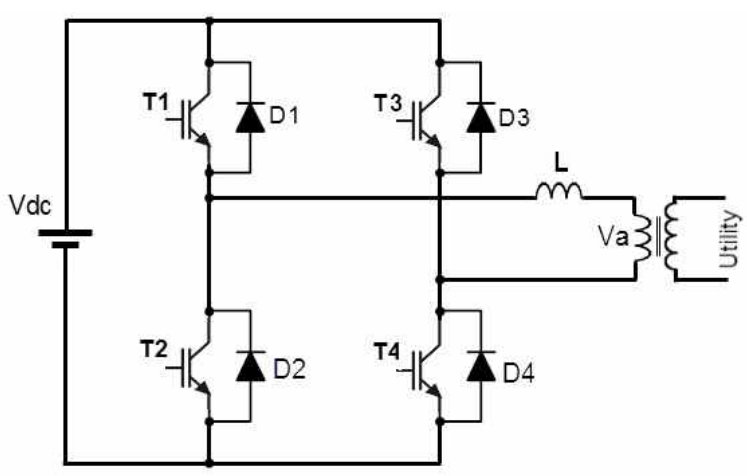

Fig. 1. Single phase grid-connected VSI.

TABLE I

Single Phase GRID-CONNECTED INVERTER’s TRADATIONAL OPERATIONAL MODE

\begin{tabular}{|c|l|l|l|l|l|l|}
\hline Mode & $\mathrm{T} 1$ & $\mathrm{~T} 2$ & $\mathrm{~T} 3$ & $\mathrm{~T} 4$ & $\mathrm{~V}_{\text {op }}$ & Half-cycle \\
\hline 1 & ON & OFF & OFF & ON & Vdc & positive \\
\hline 2 & OFF & OFF & OFF & ON & 0 & positive \\
\hline 3 & OFF & ON & ON & OFF & - Vdc & negative \\
\hline 4 & OFF & ON & OFF & OFF & 0 & negative \\
\hline
\end{tabular}

The authors of [12] proposed an algorithm for direct implementation of a predictive current controller in a microprocessor for load situation where the load voltage is known. This method compensates the errors caused by digital sampling and computing delays. The algorithm uses the results of previous switching cycles to estimate both the next grid voltage and load current. In [11], a predictive current controller with better robustness to parameters mismatch is proposed. The sampling point is set just ahead of the controlling point by the period of the computation delays. With this assumption, the measured values of the current and grid voltage are available up to the instant before the calculation proceeds to predict the demanded output voltage of the inverter. Many efforts have been done in [11] and [12] to predict an average value of the grid voltage (Va) during each sampling period to obtain a robust predictive current controller. In this work, $\mathrm{Va}$ is sampled at the beginning of the sampling period and it is kept constant during the sampling period as well as the reference and actual currents. This assumption greatly decreases the computation times, especially in the experimental work, with negligible side effects on the system performance.

\section{Single-PhaSe FULL-BRIDGE GRID-CONNECTED VSI}

The single-phase full bridge voltage source inverter topology is shown in Fig. 1. It is composed of a dc voltage source; four power switches T1, T2, T3, and T4 and four diodes D1, D2, D3, and D4. The inverter output is connected to the grid through a filter inductor $\mathrm{L}$ and a step up transformer.

\section{A. Bi-level and Tri-level Operation of VSI}

Bi-level operation can be obtained by switching T1 and T4 at the same time to get $+\mathrm{Vdc}$ on the inverter output, whilst switching T3 and T2 together to get $-\mathrm{Vdc}$ on the inverter output. In tri-level operation, the full-bridge inverter's operation can be divided into four modes [9]: two modes in the positive half cycle and two modes in the negative half cycle as shown in Table I.

Tri-level operation is more complicated than bi-level operation. Tri-level grid-connected inverters exhibit superior performance over bi-level equivalents due to their decreased current ripple, decreased switch stresses and tighter switching bandwidth. The main disadvantage of tri-level over bi-level is the added complexity of maintaining control of the current near the voltage zero crossing [5]. In the present study, to find a simple solution without the addition of any control complexity, another two modes of operation are added to the four previous modes as will be shown in section IV. We named this mode as "six mode of operations" against the old tri-level "four mode of operations".

\section{Proposed PREDictive CURRENT CONTROL TECHNIQUE FOR SINGLE PHASE VSI}

Predictive controllers calculate the inverter voltages required to force the measured currents $(i)$ to follow the reference current $\left(i_{\text {ref }}\right)$. The deference between $i_{\text {ref }}$ and $i$ is the current error $\left(i_{\text {err }}\right)$. In tri-level operation, the inverter output can be regarded as a vector which has three states, v1, v2 and v0. Where $v 1=V_{d c}$ during the positive half cycle, $v 2=-V_{d c}$ during the negative half cycle, and $v 0=0$

\section{A. Switching Time Calculations}

During the application of the non-zero voltage vectors (v1 and v2) the inverter's equation is:

$$
s V_{d c}-v_{a}=L \frac{d i_{1}}{d t}
$$

Where $s=1$ for the positive half cycle, $s=-1$ during the negative half cycle and $d i_{1} / d t$ is the rate of change for the inverter output current during the application of the nonzero vector. Then from (1):

$$
\frac{d i_{1}}{d t}=\frac{s V_{d c}-v_{a}}{L}
$$

and during the application of the zero vector: 


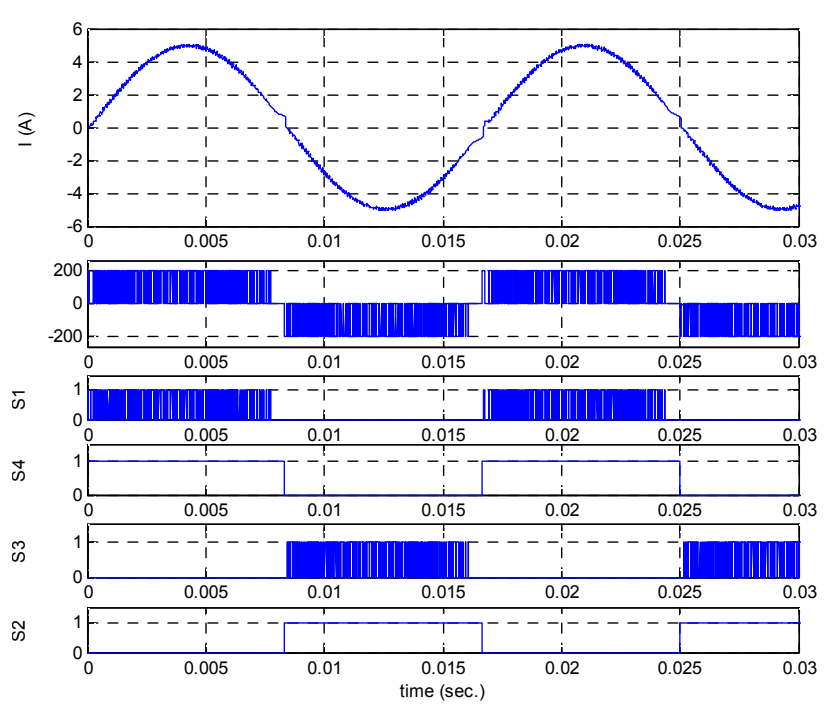

Fig. 2 inverter output current $(\mathrm{THD}=2.6 \%)$, inverter output voltage, T1, T4, T3, and T2 control signals (four modes of operation)

$$
\frac{d i_{2}}{d t}=\frac{0-v_{a}}{L}
$$

Where $d i_{2} / d t$ is the rate of change of the inverter output current during the application of the zero vector.

$$
i_{\text {err }}=i_{\text {ref }}-i
$$

To compensate the current error during the switching time period $\mathrm{T}$, the following equation can be used:

$$
i_{\text {err }}=\frac{d i_{1}}{d t} T_{o n}+\frac{d i_{2}}{d t} T_{\text {off }}
$$

where $T_{\text {on }}$ is the time period required for applying the nonzero vector and $\mathrm{T}_{\text {off }}$ is the time period required for applying zero vector. $d i_{1} / d t$ and $d i_{2} / d t$ are the rates of change in the inductor current $(i)$ during $\mathrm{T}_{\text {on }}$ and $\mathrm{T}_{\mathrm{off}}$, respectively, and $v_{a}$ is the grid voltage.

For a constant switching frequency the switching time period $\mathrm{T}$ can be obtained as follows:

$$
T=T_{\text {on }}+T_{\text {off }}
$$

From equations (2), (3), (5), and (6) the required time periods can be obtained as follows:

$$
\begin{gathered}
T_{o n}=\frac{L \times i_{\text {err }}}{s V_{d c}}+\frac{v_{a}}{s V_{d c}} T \\
T_{o f f}=T-T_{o n}
\end{gathered}
$$

According to (7) and (8) based on Table I, PWM control signals with a duty ratio of $T_{\text {on }} / T$ can be used to drive T1

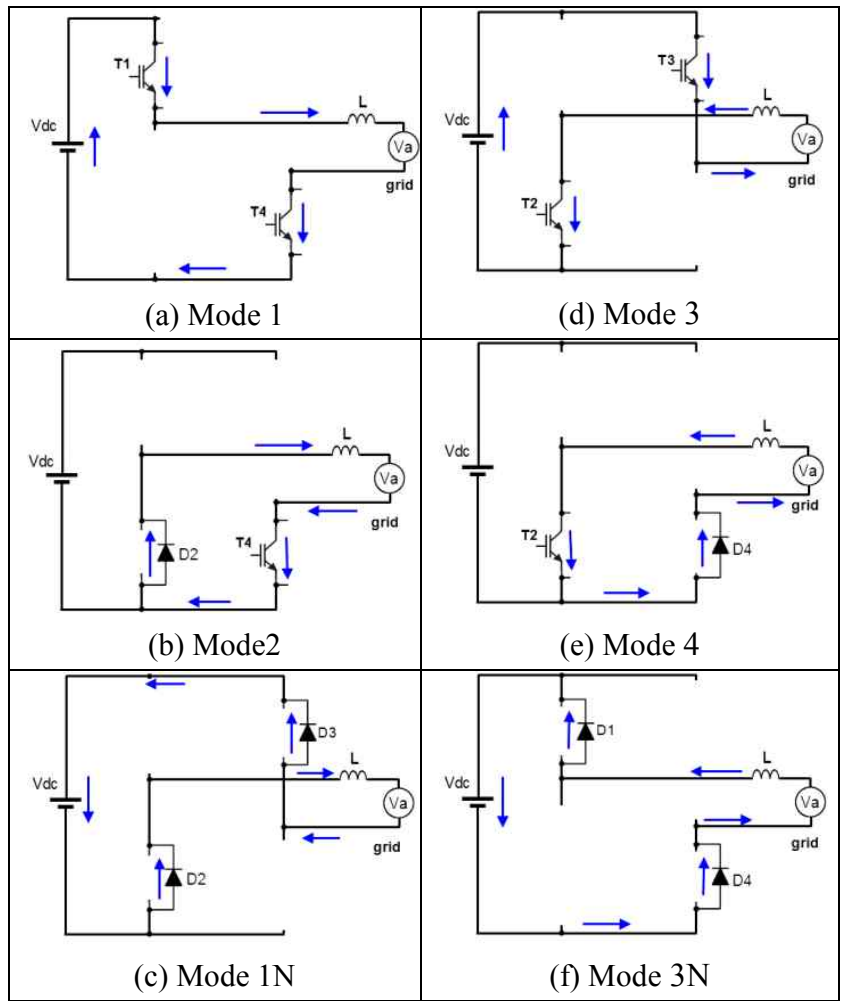

Fig. 3. Modes of operation of the proposed predictive current controller.

(in the positive half cycle) and T3 (in the negative half cycle) to compensate the current error.

\section{SimUlation RESUlts}

The proposed predictive current controller is verified by simulation using MATLAB/SIMULINK. For all of the simulations, the dc voltage and grid voltage are $200 \mathrm{~V}$ and $110 \mathrm{~V}$, respectively, and the filter inductor is $18 \mathrm{mH}$. The sampling period is set to $100 \mu$ sec. Fig. 2 shows the advantages of using the tri-level PWM switching strategy in terms of a reduced current ripple and a halved "effective" switching frequency. The THD in this case is about $2.6 \%$. The main disadvantage of tri-level switching is controlling the power switches at the voltage crossover as shown in Fig.2. In Fig. 2, it is clear that the inverter output voltage, around the zero crossing points, is zero for a time period depending mainly on the inductor value L. As L increases, the current distortion at zero crossing increases. This paper introduces a simple and effective solution for this problem as will be shown in the next section.

\section{A. Proposed Tri-level Switching Strategy}

Around the voltage crossover (zero-crossing points), the first term of (7) is the only effective term (because $v_{a} \cong 0$ ). With a negative error current, Ton will be negative. In practical operation the Ton time cannot be negative. 


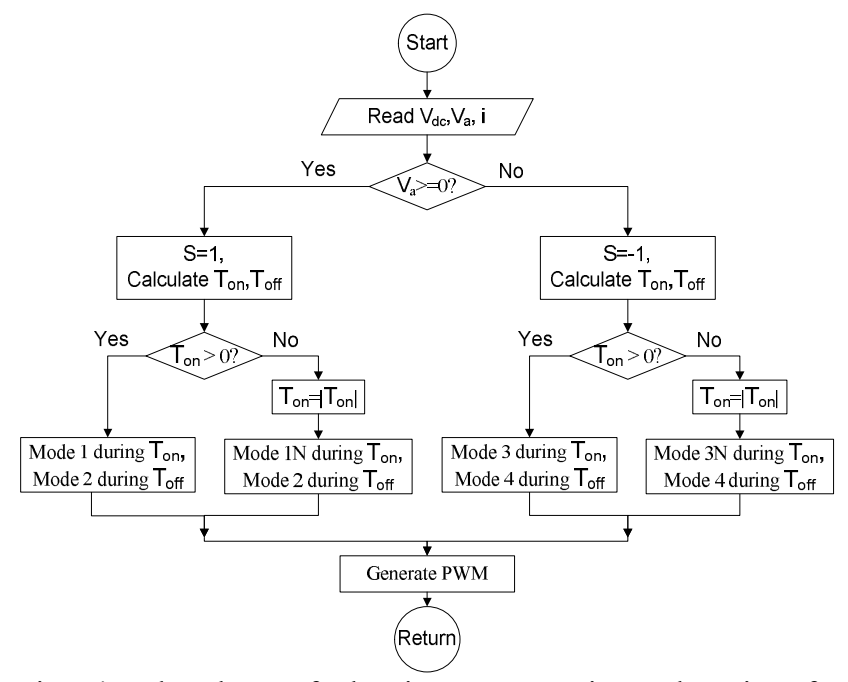

Fig. 4. Flowchart of the interrupt service subroutine for six-modes of operation to generate PWM.
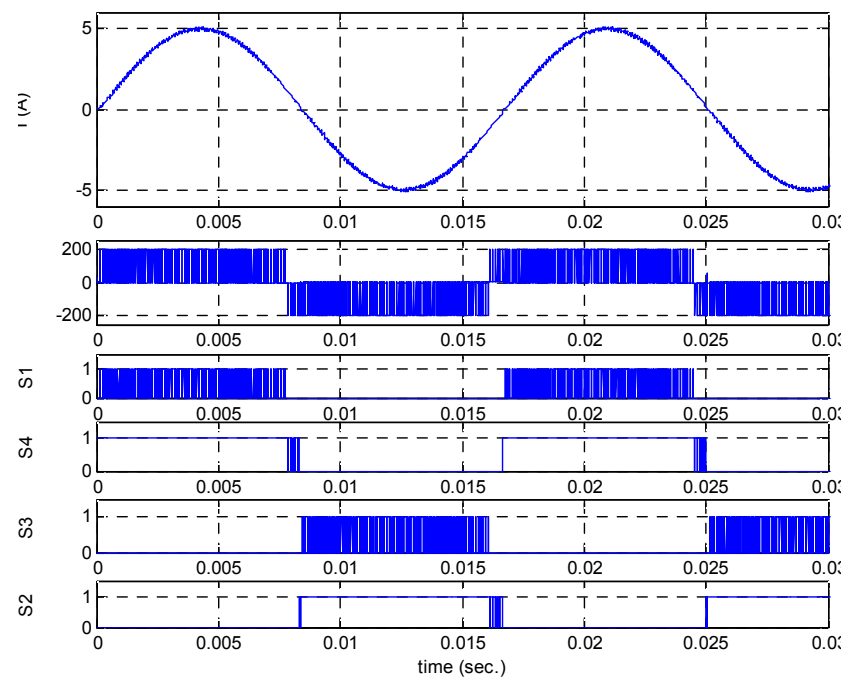

Fig. 5. Inverter output current $(\mathrm{THD}=1.8 \%)$, inverter output voltage, T1, T4, T3, and T2 control signals (six modes of operation)

Therefore, the controller will make it equal to zero. In this case and during the positive half cycle, T1 is turned off and the controller is unable to decrease the actual current to follow the reference current. As a result, dips in the current plot are found around the zero crossing in Fig. 2. The inverter output voltage around the zero crossing is zero as shown from the second plot of Fig. 2. To solve this problem in the positive half cycle, the inverter output voltage should be negative to rapidly decrease the actual current. This can be done simply by turning off T4 (T1 is off) resulting (mode $1 \mathrm{~N}$ ) in Fig. 3. The turning off time of T4 in this case, is equal to the absolute value of the calculated negative value of Ton according to (7).

The same procedure can be done at the end of the negative half cycle when a positive error current occurs. Then Ton will be negative. In this case the inverter output voltage should be

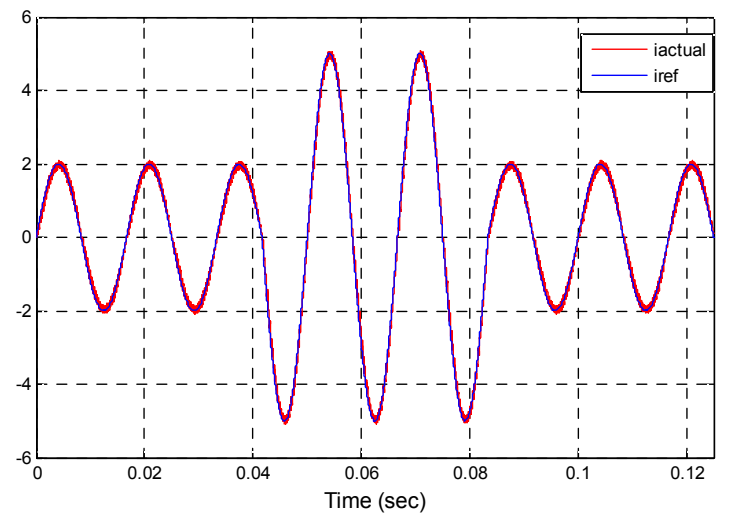

Fig. 6. Transient response for step change in reference current.

positive to rapidly increase the actual current. This can be done simply by turning off $\mathrm{T} 2$ (T3 is off) resulting (mode $3 \mathrm{~N}$ ) in Fig. 3. The turning off time of $\mathrm{T} 2$ in this case, is equal to the absolute value of the calculated negative value of Ton according to (7). Fig. 4 shows a flowchart of the procedure for six modes of operation and the generation of PWM signals to the four switches. Applying this solution, two modes of operations (mode $1 \mathrm{~N}$ and mode $3 \mathrm{~N}$ in Fig.3) are added to the previous four modes of operation resulting in six modes of operations as shown in Fig. 3. Fig. 5 shows that the discontinuity of the inverter output voltage disappears and that the problem is solved. The current THD decreased from $2.6 \%$ to $1.8 \%$ which is another contribution of this study.

It should be mentioned that a great deal of effort has been exerted in [11] and [12] to predict the average value of $\mathrm{Va}$ during each sampling time to obtain a robust predictive current controller. In this study, $\mathrm{Va}$ is sampled at the beginning of the sampled period and is kept constant during the sampling period. From (7), it is found that the difference in Ton between the two cases has a maximum value of 1.5 $\mu \mathrm{sec}$ with a current error of about $20 \mathrm{~mA}$ in the modeled system. Bode, et al. [14] have proposed a new predictive current regulation algorithm for single- and three-phase grid connected inverters. In their paper, they proposed that, instead of zero, the targeted current error at the end of the period is made equal to half the difference of the previous two current errors. In this paper, $i_{\text {ref }}$ and $i$ are sampled at the beginning of the sampling period and are kept constant during the sampling period. This assumption greatly decreases the computation time, especially in the experimental work, with negligible effects on the system performance.

\section{EXPERIMENTAL SETUP}

Fig. 7 illustrates the configuration of the implemented system. The prototype system includes an IGBT inverter circuit module, 4-channel isolation amplifier module, a 


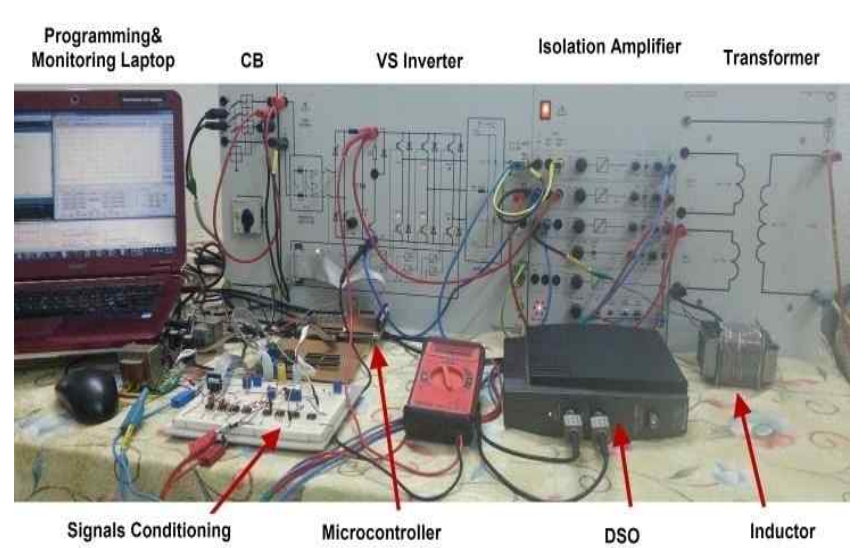

Fig. 7. Experimental grid-connected VSI setup circuit.

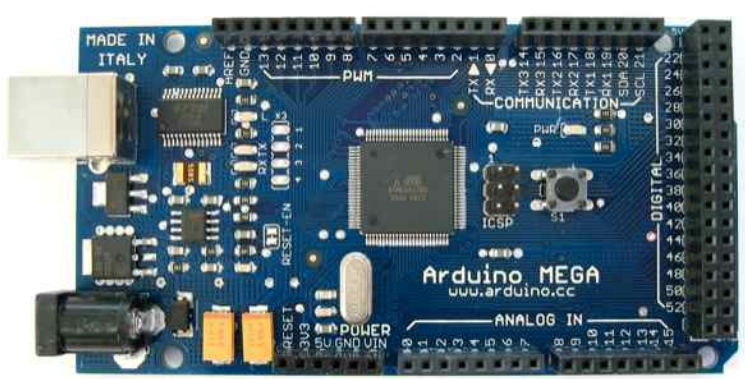

Fig. 8. Arduino ATmega1280 based microcontroller board.

TABLE II

MicrCoCONTROLLER BOARD SPECIFICATIONS

\begin{tabular}{|l|l|}
\hline Board & Arduino \\
Device & ATmega1280 \\
Device Type & AVR, Fixed point, 8-bit \\
Clock & $16 \mathrm{MHz}$ \\
SRAM & 8 Kbytes \\
EEPROM & 4 Kbytes \\
Flash & 128 Kbytes \\
A/D & 16 channel, 10-bit resolution \\
Timers & Two 8-bit \& Four 16-bit timer/counter \\
PWM & 12 PWM channels \\
I/O lines & 86 \\
Communication & USB \\
\hline
\end{tabular}

microcontroller-based control and driver module, signal conditioning circuits, and a filter inductor. The input of the inverter is connected to a single-phase controlled rectifier with a variable dc link voltage up to $355 \mathrm{~V}$. The inverter output voltage is $127 \mathrm{~V}, 8 \mathrm{~A} \max$ current, up to $20 \mathrm{kHz}$ switching frequency. The output of the inverter is connected to the grid through a step up transformer $110 / 220 \mathrm{~V}$. The nominal grid voltage is $220 \mathrm{~V}$, the grid frequency is $60 \mathrm{~Hz}$ and the inductor inductance is $18 \mathrm{mH}$. The inverter is equipped with hardware protections.

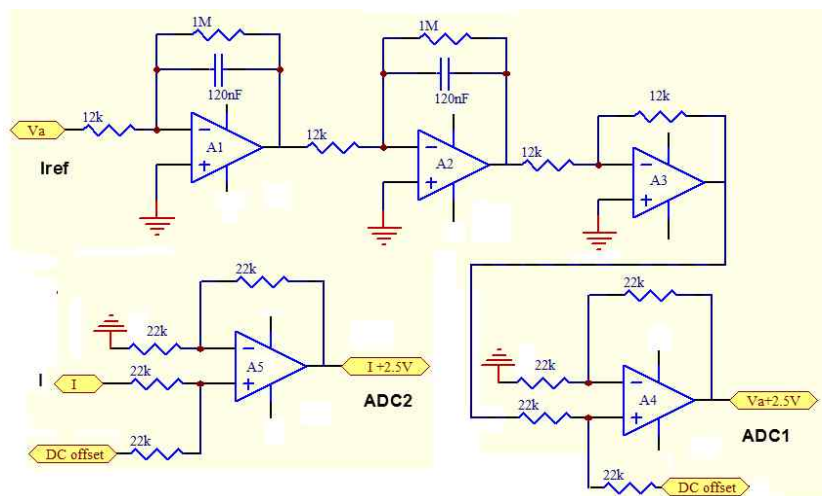

Fig. 9. Experimental signal conditioning circuits.

\section{A. Microcontroller Board}

The control of the system is done using Arduino Mega microcontroller board based on AVR, 8-bit ATmega1280 microcontroller device. The microcontroller board is shown in Fig. 8 where its specifications are listed in Table II.

The microcontroller adds simplicity to the control system. Instead of the complex and more expensive digital signal processors (DSP) - as many literatures work - a simple and cheap microcontroller board which can do the same control work with the same switching frequency without loss of control functionality is used.

Two 16-bit timers/counters are used to generate 4 PWM signals (S1 to $\mathrm{S} 4$ ) for driving the transistors (T1 to T4). Each counter has 4 isolated channels, and each of them can be programmed individually. Timer/counter 3 (channels A and $\mathrm{B}$ ), and Timer/counter 4 (channels $\mathrm{A}$ and $\mathrm{B}$ ) are used to generate the required PWM signals. The counters are programmed to run in Phase and Frequency Correct PWM Mode. If the counter is loaded with a count, it counts up from zero till the loaded count then counts down again to zero then an over flow interrupt occurs. In this experimental work, the whole interrupt period is set to $100 \mu$ s for the selected sample time T. As a result, the switching frequency will be $10 \mathrm{kHz}$. An output compare register is loaded with a compare number, on compare match a set or reset of the output pin (OC3A, $\mathrm{OC} 3 \mathrm{~B}, \mathrm{OC} 4 \mathrm{~A}$ or $\mathrm{OC} 4 \mathrm{~B}$ ) occurs as programmed. Counter 3 is programmed to set on compare match, and counter 4 is programmed to clear on compare match. The compare registers of the four channels are updated with a compare number that corresponds to Ton in each sample. At the beginning of the sampling period, the grid voltage and actual current are sampled through two A/D channels. Eq. (7) is used to calculate the pulse width of the controlling signal that loaded to the counter compare registers. In the same sampling period, as soon as the calculations are finished, the four counter channels are updated. In the suggested switching strategy, there is no need for any dead time between $\mathrm{T} 1$ and $\mathrm{T} 2$ or between $\mathrm{T} 3$ and $\mathrm{T} 4$. 


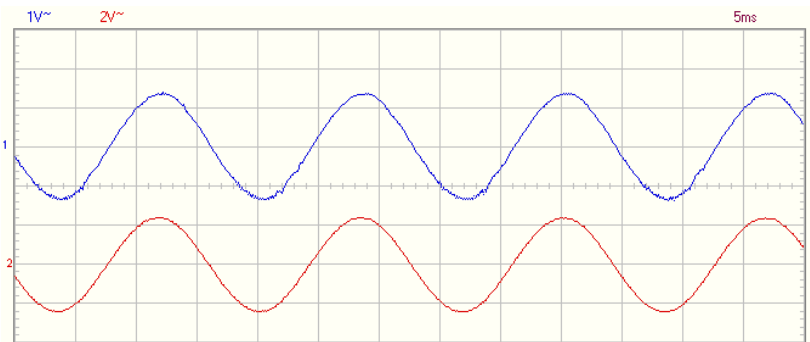

Fig. 10. Experimental input and output of the signal conditioning circuit.

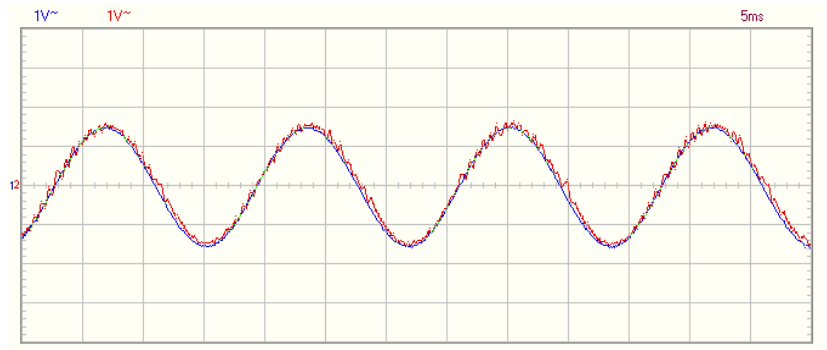

Fig. 11. Experimental reference and actual current of the predictive current controller (four modes of operation), scale: $1 \mathrm{~A} / \mathrm{div}, 5 \mathrm{~ms} / \mathrm{div}$.

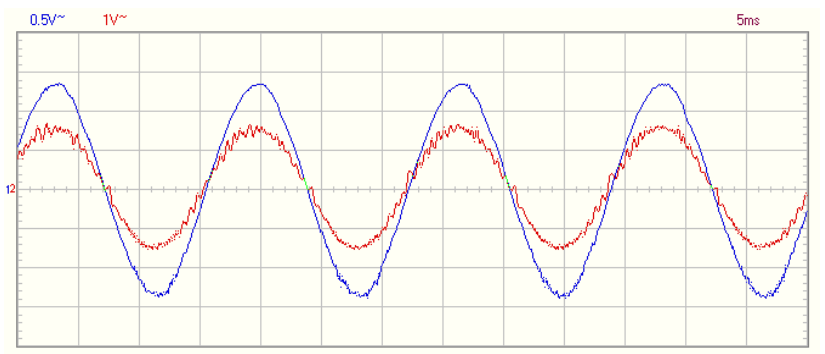

Fig. 12. Experimental grid voltage and inverter output current (four modes of operation), scale: $50 \mathrm{~V} / \mathrm{div}, 1 \mathrm{~A} / \mathrm{div}, 5 \mathrm{~ms} / \mathrm{div}$.

\section{B. Signal Conditioning Circuits}

In operation, the signal from grid voltage is noisy and needs filtering. Instead of using a PLL with complex computations, two successive analog integrators with an adjustable dc offset are used to provide a smooth signal representing the grid voltage Va. After scaling, this signal can be used as a current reference for unity power factor operations. The grid voltage and the actual current signals are bipolar signals $( \pm 5 \mathrm{~V})$ but the $\mathrm{A} / \mathrm{D}$ of the microcontroller accepts only unipolar signals $(0:+5 \mathrm{~V})$. As a result, a dc offset and scaling are added for proper operation as shown in Fig. 9.

\section{EXPERIMENTAL RESULTS}

The proposed predictive current control strategy is tested on a prototype grid-connected single-phase IGBT inverter. The experimental results are collected using an USB digital storage scope (USB-DSO).

Fig. 10 illustrates signal conditioning circuit input and output waveforms. The input is the grid voltage signal and

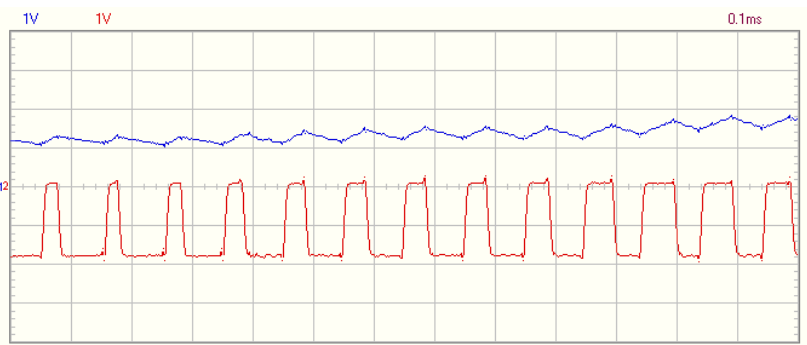

Fig. 13. Experimental inverter output current and voltage, scale: $1 \mathrm{~A} / \mathrm{div}, 100 \mathrm{~V} / \mathrm{div}, 100 \mu \mathrm{s} / \mathrm{div}$.

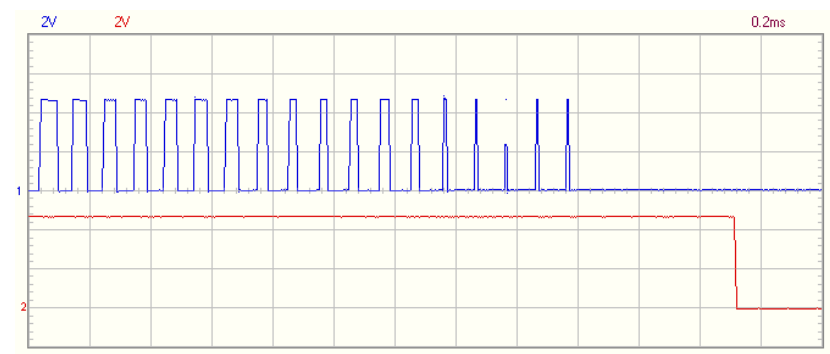

Fig. 14. Experimental gate pulses for $\mathrm{T} 1 \& \mathrm{~T} 4$ of the predictive current controller (four modes of operation).

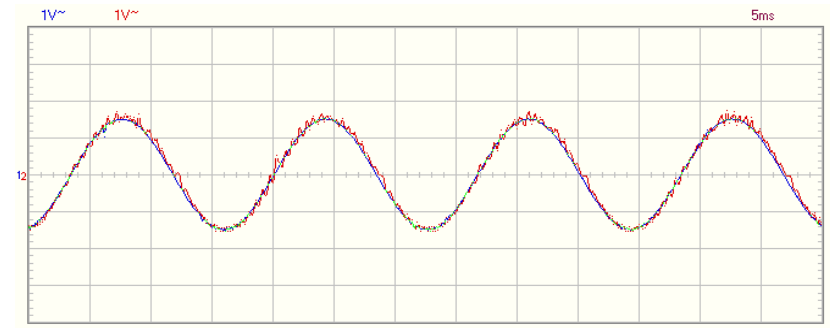

Fig. 15. Experimental reference and actual current of the proposed predictive current controller (six modes of operation), scale: $1 \mathrm{~A} / \mathrm{div}, 5 \mathrm{~ms} / \mathrm{div}$.

the output is the filtered signal. The effectiveness of the suggested conditioning circuit in terms of providing a pure signal representing the grid voltage is shown in Fig.10. The upper trace for the grid voltage signal has some distortion, whereas the lower one is a pure sine wave filtered signal that is used for the current signal reference with some scale.

Fig. 11 shows the reference and actual current injected to the grid using the proposed technique where four modes of operations are used. The current ripple content in Fig. 11 shows the superiority of the proposed technique.

Fig. 11 demonstrates that the proposed predictive current controller technique can be implemented using a fixed-point microcontroller to obtain excellent results. As a result of using four modes of operations, dips in the actual current (Fig. 11) exist near the zero crossing points as shown in Fig. 2. of the simulation results.

Fig. 12 shows the grid voltage and the inverter output current, where a unity power factor operation is obtained.

Fig. 13 shows the inverter output current and the inverter output voltage. The time scale is $100 \mu \mathrm{s} / \mathrm{div}$. The inverter output voltage switches between zero and $-\mathrm{Vdc}$. The rate of 


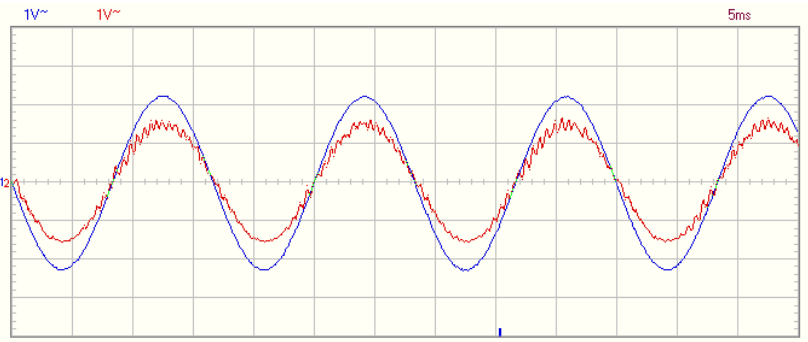

Fig. 16. Experimental grid voltage and inverter output current (six modes of operation), scale: $50 \mathrm{~V} / \mathrm{div}, 1 \mathrm{~A} / \mathrm{div}$, and $5 \mathrm{~ms} / \mathrm{div}$.

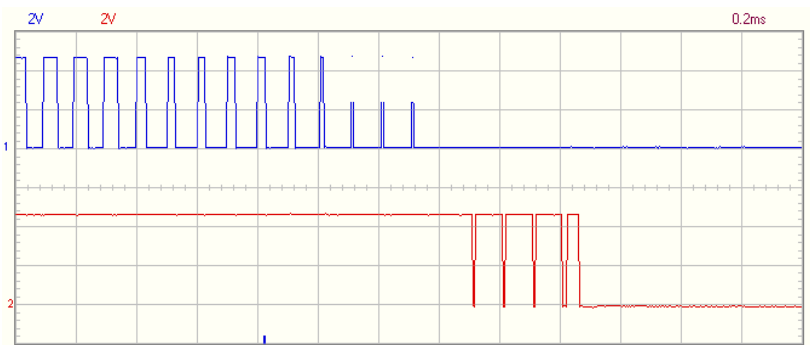

Fig. 17. Experimental gate pulses for $\mathrm{T} 1 \& \mathrm{~T} 4$ of the proposed predictive current controller (six modes of operation).

changes of the inverter output current during Ton and Toff times are clear in this figure. Fig. 13 also shows that the sampling time is $100 \mu \mathrm{sec}$ ( $10 \mathrm{kHz}$ switching frequency).

Fig. 14 shows the control signals for transistor $\mathrm{T} 1$ and transistor T4 while using four modes of operations. This figure shows the discontinuity of the PWM signals for T1 near the zero crossover point. T4 is in the $\mathrm{ON}$ state during the entire positive half cycle. It should be mentioned that there is no need for any dead time in the suggested switching strategy.

Figs. 15, 16 and 17 show the results of the proposed predictive current control scheme while using six modes of operations. Fig. 15 shows the reference and actual current, Fig. 16 shows the grid voltage and the inverter output current, and Fig. 17 shows the gate pulses for T1 and T4. It is shown in Fig. 17 that there are pulses for T4 (T4 in the OFF state for multiple times) near the zero crossover point as suggested in the proposed switching strategy.

\section{CONCLUSIONS}

An improved predictive current control technique applied to a single phase grid connected voltage source inverter is proposed in this paper. The proposed technique is suitable for practical implementations using a fixed point microcontroller to achieve excellent current performance with minimal harmonic distortion. The proposed technique modifies the traditional tri-level switching strategy with four modes of operation by adding another two modes to be "six modes of operation" to enhance the current performance. The two supplementary modes of operation are added without increasing control complexity. The suggested switching strategy is free of dead time. Simulation and experimental results have been presented to confirm the excellent operation of the proposed control technique and the suggested switching strategy.

\section{REFERENCES}

[1] D. Dong, T. Thacker, I. Cvetkovic, R. Burgos, D. Boroyevich, F. Wang, and G. Skutt, "Modes of operation and system-level control of single-phase bidirectional pwm converter for microgrid systems," IEEE Trans. Smart Grid, Vol. 3, No. 1, pp. 93-104, Mar. 2012.

[2] H. Kim, "Filter design for grid-connected single-phase inverters," Journal of Power Electronics, Vol. 9, No. 4, pp. 623-630, Jul. 2009.

[3] F. Blaabjerg, R. Teodorescu, M. Liserre, and A. V. Timbus, "Overview of control and grid synchronization for distributed power generation systems," IEEE Trans. Ind. Electron., Vol. 53, No. 5, pp. 1398-1409, Oct. 2006.

[4] S. Jena, B. C. Babu, A. K. Naik, and G. Mishra, "Performance improvement of single-phase grid-Connected PWM inverter using PI with hysteresis current controller," Energy, Automation, and Signal (ICEAS), 2011 International Conference on Digital Object Identifier, 2011.

[5] D. M. Baker, V. G. Agelidis, and C. V. Nayar, "A comparison of tri-level and bi-level current controlled grid-connected single-phase full-bridge inverters," IEEE Proceedings of the International Symposium on Industrial Electronics, ISIE'97, Vol. 2, 1997.

[6] D. Marandi, T. N. Sowmya, and B. C. Babu, "Comparative study between unipolar and bipolar switching scheme with LCL filter for single phase grid connected inverter system," IEEE Students' Conference on Electrical, Electronics and Computer Science 2012 (SCEECS), 2012.

[7] Y. C. Kim, L. Jin, J. Lee, and J. Choi, "Direct digital control of single-phase AC/DC PWM converter system," Journal of Power Electronics, Vol. 10, No. 5, pp. 518-527, Sep. 2010.

[8] A. K. Gola and V. Agarwal, "Implementation of an efficient algorithm for a single phase matrix converter," Journal of Power Electronics, Vol. 9, No. 2, pp. 198-206, Mar. 2009

[9] H. M. Kojabadi, B. Yu, I. A. Gadoura, L. Chang, M. Ghribi, "A novel DSP-based current-controlled PWM strategy for single phase grid connected inverters," IEEE Trans. Power Electron., Vol. 21 , No. 4, pp. 985-993, Jul. 2006.

[10] B. Yu, "Predictive Current Controlled PWM Strategy for Grid-connected Single-Phase Inverter," M.Sc. thesis, Univ. New Brunswick, Fredericton, NB, Canada, 2004.

[11] B. Yu and L. Chang, "Improved predictive current controlled PWM for single- phase grid-connected voltage source inverters," IEEE 36th Power Electronics Specialists Conference, PESC '05, 2005.

[12] D. G. Holmes, and D. A. Martin, "Implementation of a direct digital predictive current controller for single and three phase voltage source inverters," Industry Applications Conference, IEEE Thirty-First IAS Annual Meeting Conference Record of the 1996, IAS '96, 1996.

[13] T.-F. Wu, K.-H. Sun, C.-L. Kuo, and C.-H. Chang, "Predictive current controlled 5-kW single-phase bidirectional inverter with wide inductance variation for 
DC-microgrid applications," IEEE Trans. Power Electron., Vol. 25, No. 12, pp. 3076-3084, Dec. 2010.

[14] G. H. Bode, P. C. Loh, M. J. Newman, and D. G. Holmes, "An improved robust predictive current regulation algorithm," in Proc. 5th Int. Conf. Power Electron. Drive Syst. (PEDS'03), Vol. 2, pp.1058-1063, 2003.

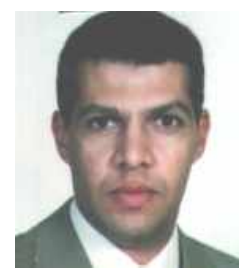

Yousry Atia was born in Egypt, in 1964. He received his B.Sc from the Faculty of Engineering, Minoufiya University, Shebin El Kom, Egypt, in 1987. He received his M.Sc and Ph.D. from the Department of Electrical Power and Machines, Faculty of Engineering, Cairo University, Cairo, Egypt, in 1995 and 2000, respectively. He is currently working as an Associate Professor Researcher in the Department of Photovoltaic Cells, Electronics Research Institute, Cairo, Egypt. His current research interests include renewable energy, power electronics, drives, electrical machines, system design and distributed grid-connected systems.

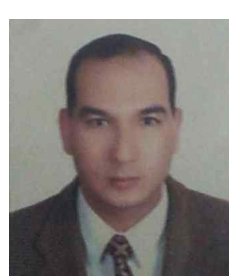

Mahmoud Salem received his B.Sc. in Electrical Engineering from the Faculty of Engineering, Minoufiya University, Shebin El Kom, Egypt, in 1988. He received his M.Sc. and Ph.D. in Electrical Engineering from Cairo University, Cairo, Egypt, in 1994 and 2000, respectively. He is currently working as an Associate Professor Researcher in the Department of Power Electronics, Electronics Research Institute, Cairo, Egypt. His current research interests include artificial intelligence, neural networks, control systems, electrical drives, digital controller hardware, and distributed grid-connected systems. 